\title{
Quantitative evaluation of the petal shape variation in Primula sieboldii caused by breeding process in the last 300 years
}

\author{
Y Yoshioka ${ }^{1}, \mathrm{H}$ Iwata $^{2}, \mathrm{R}$ Ohsawa ${ }^{1}$ and S Ninomiya ${ }^{2}$ \\ ${ }^{1}$ Graduate School of Life and Environmental Sciences, University of Tsukuba, 1-1-1 Tennodai, Tsukuba, Ibaraki 305-8572, Japan; \\ ${ }^{2}$ Department of Information Science and Technology, National Agricultural Research Center, 3-1-1 Kannondai, Tsukuba, \\ Ibaraki 305-8666, Japan
}

\begin{abstract}
Primula sieboldii (E. Morren) has been a popular garden plant at least since the Edo period, about 300 years ago. We compared petal form between cultivars and wild populations in order to characterise the changes that have occurred during domestication. The comparison was made using EFPCA analysis, which describes overall petal shape mathematically by transforming petal contour coordinates into elliptic Fourier descriptors; it subsequently summarises these descriptors by principal component analysis (PCA). Rearing cultivars in a common-garden experiment identified the PCs with a substantial genetic element. A clear heritable component was detected for the PCs characterising symmetrical variation in flower shape, but not the asymmetrical variation. Wild populations of this species have become
\end{abstract}

endangered owing to habitat destruction by human activity, and many lowland floodplain habitats have been lost. Variation within the remaining wild populations was significantly lower than in the cultivars for PC1 (aspect ratio), PC3 (curvature of proximal and distal parts) and petal area; but not for PC2 (depth of head notch) and PC4 (position of the centre of gravity). The shifts in petal form from the wild populations to the cultivars parallel those seen in other croptypes following domestication, including an increase in size and diversity of forms: cultivars have shallower head notches, more fan-shaped petals and larger petals than do wild $P$. sieboldii.

Heredity (2005) 94, 657-663. doi:10.1038/sj.hdy.6800678

Published online 13 April 2005

Keywords: Primula sieboldii; petal shape; fourier descriptors; principal component; flower; domestication

\section{Introduction}

How has petal-form variation arisen from wild populations in the process of floricultural crop breeding? Along with flower colour and pattern, petal form, that is, shape and size, is one of the most important targets in floricultural crop breeding. Some cultivars are quite distinct from their original wild types. Gigantism and morphological diversification in the plant organs, such as seeds, fruits and leaves, are well known as one of major elements in the 'domestication syndrome' of food crops (Hawkes, 1983). Similar phenomena are to be expected in floriculture crops, especially in characteristics related to aesthetic quality. However, few studies have demonstrated change in the floral characteristics under domestication by comparing variations in wild populations and cultivars. Crop evolution studies have important consequences for genetic conservation and breeding, and allow us to identify segments of the germplasm that are not represented, or insufficiently represented, in genetic resource collections, such as wild ancestral populations (Gepts, 1993). Moreover, detailed comparison of floral characteristics in cultivars and wild populations provide

Correspondence: S Ninomiya, Department of Information Science and Technology, National Agricultural Research Center, 3-1-1 Kannondai, Tsukuba, Ibaraki 305-8666, Japan. E-mail: snino@affrc.go.jp Received 28 August 2004; accepted 28 February 2005; published online 13 April 2005 us with important information on historical breeding processes and traditional consumer preferences.

Primula sieboldii (E. Morren), a perennial clonal herb grown widely in Japan and Northeast Asia, is an appropriate species to investigate the effect of domestication and breeding on floral characteristics in floriculture crops. Many cultivars of $P$. sieboldii exist, and wild ancestral populations of those cultivars are still available. In Japan, this species has been popular as a garden plant since the Edo period, about 300 years ago (Suzuka, 1975; Torii, 1985). Cultivation of the species in Japan was first described in 1681 in the Japanese gardening book 'KadanKoumoku'. Descriptions of $P$. sieboldii cultivars were written in 1695 and in the 1700s (Torii, 1985), so breeding is likely to have begun before 1695 . P. sieboldii cultivars are considered to have originated from particular wild populations along the Arakawa River (Figure 1; Torii, 1985; Honjo et al, 2002). Since this initial domestication more than 300 cultivars have been bred. However, in recent years, wild populations of this species have become endangered owing to habitat destruction by human activity, and many lowland floodplain habitats of the plant along the Arakawa River have been destroyed (Washitani, 1998).

Any comparative study of petal-form variation must depend on an accurate evaluation of objective characteristics. We previously reported that the use of elliptic Fourier descriptors and principal component analysis (EF-PCA) was effective in the quantitative evaluation of 


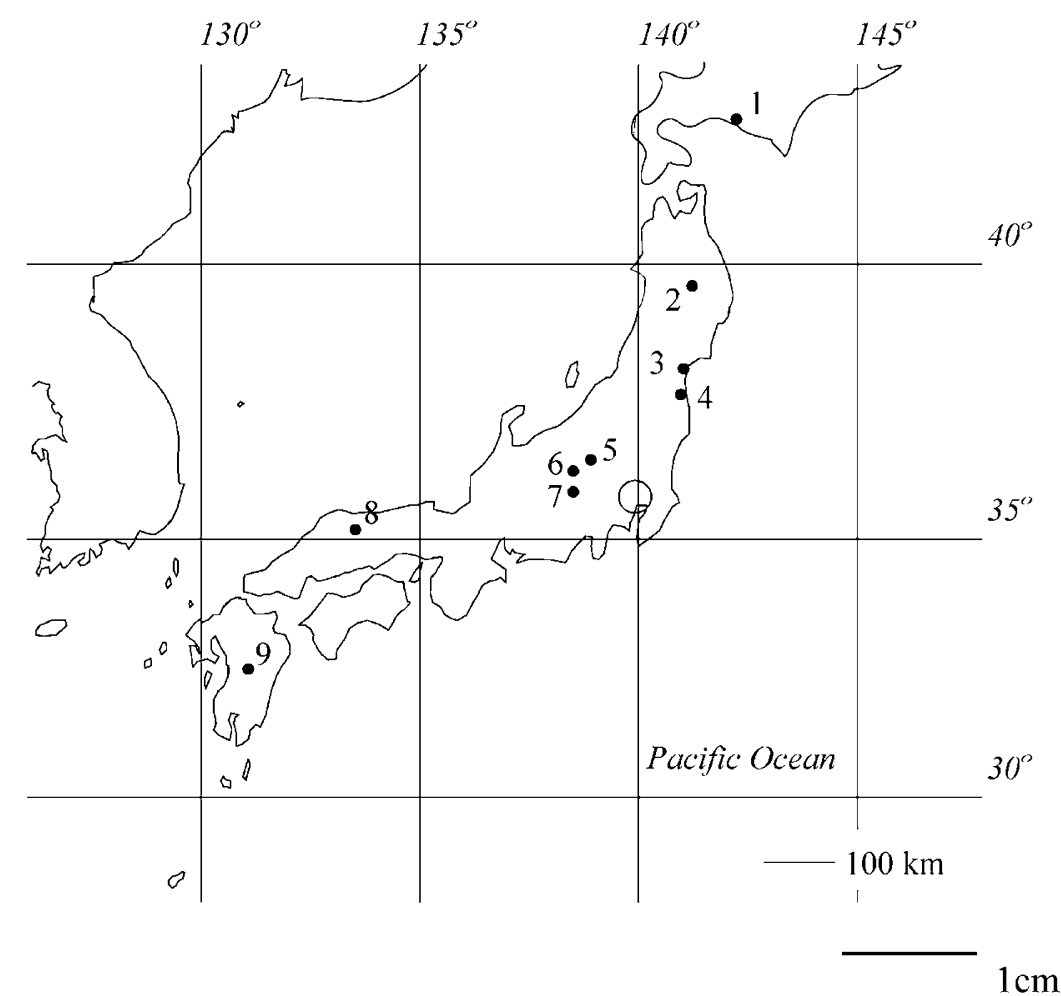

Figure 1 Locations of the wild populations of Primula sieboldii used in this study. Wild populations: $1=$ Mombetsu; $2=$ Takizawa; $3=$ Sendai; $4=$ Soma; $5=$ Kurabuchi; $6=$ Karuizawa; $7=$ Minamimaki; $8=$ Maniwa; $9=$ Aso. $\bigcirc$ : The wild populations along Arakawa River that have virtually been destroyed.

P. sieboldii petal shape (Yoshioka et al, 2004). EF-PCA has two major advantages: first, it can detect small variations in shape, and second, it can be used to evaluate the shapes of objects independently of their size. A procedure based on elliptic Fourier descriptors (EFDs) (Kuhl and Giardina, 1982) is commonly used to analyse the shape of various plant organs. This procedure describes an overall shape mathematically by transforming contour coordinates into Fourier coefficients. The application of EFDs to plant organ shape analysis was first attempted by White et al (1988) in Betula leaf. EF-PCA, as suggested by Rohlf and Archie (1984), has been applied to the evaluation of several plant organs, such as Begonia leaf (McLellan, 1993), soybean leaflet (Furuta et al, 1995), buckwheat kernel (Ohsawa et al, 1998), radish root (Iwata et al, 1998), yam tuber (Toyohara et al, 2000) and citrus leaf (Iwata et al, 2002). Recently, Iwata and Ukai (2002) developed a software package, 'SHAPE', for the quantitative evaluation of biological shapes on the basis of EF-PCA.

Our aim was to use EF-PCA to accurately compare petal-form variation in cultivars and wild populations of $P$. sieboldii and to determine the effect of domestication and breeding on the floral characteristics of floriculture crops. In addition, we discuss the breeding history of this plant in terms of petal form. First, we quantified petal shape variation by EF-PCA. Next, we used nested ANOVA to determine the relative contributions of genotype and environment to petal shape variation, because an assessment of the strength of genetic control is necessary to confirm the validity of the principal components (PCs) chosen. Finally, to evaluate petal shape diversity and detect petal shape differentiation between the cultivars and wild populations, we performed tests for equal variance and two-sample $t$-tests. We also compared variation in petal area in a similar fashion.

\section{Materials and methods}

The 75 cultivars used are listed in Table 1. P. sieboldii E. Morren is a clonally propagated perennial that produces one to five new sprouts annually. In April 2002, when all of the 29 cultivars grown at the Agriculture and Forestry Research Center, University of Tsukuba, were flowering, we randomly sampled three to five plants per cultivar and two to three flowers per plant (total: 413 flowers). The other 46 cultivars were kindly provided by the Horticultural Laboratory, Saitama Prefecture Agriculture and Forestry Research Centre in April 2003. We randomly sampled three of these plants per cultivar, and three flowers per plant (46 cultivars $\times 3$ plants $\times 3$ flowers $=414$ flowers). The data set from the 29 cultivars grown at the University of Tsukuba was not included in the nested ANOVA, because this data set had an unbalanced data structure.

We also used 809 flowers of 264 genets from nine wild Japanese populations (Figure 1). We randomly sampled two to five flowers per genet from each wild population. Ideally, we would have grown plants from the wild populations under the same conditions as those used to grow our cultivars, but we were unable to move the plants to a common research site, because $P$. sieboldii has 
been listed as VU (vulnerable) in the Japanese Plant Red List (Ministry of the Environment, 2004).

We broke up each flower into five petals and used a digital camera (COOLPIX-850, Nikon, Tokyo) to photograph the petals next to a scale marker $(10 \mathrm{~mm} \times 10 \mathrm{~mm})$. Each image was saved as an RGB colour image in BMP image format with 256 brightness levels per channel (red, green, blue). As the red-channel gave the clearest contrast between the petals and background, the RGB images were converted into binary images by applying a threshold method to the red channel. From these binary images we extracted the closed contours of the petals and chain-coded them (Freeman, 1974). The coefficients of the EFDs, which were normalised to avoid variation related to the size, rotation and starting point of the contour

Table 1 List of the cultivars used in this study

\begin{tabular}{|c|c|c|c|c|c|}
\hline No. & Cultivar & No. & Cultivar & No. & Cultivar \\
\hline 1 & Akatonbo $^{a}$ & 31 & Kazaguruma $^{a}$ & 61 & Tamahuyo \\
\hline 2 & Akegarasu $^{a}$ & 32 & Kokiden ${ }^{a}$ & 62 & Tamasango $^{a}$ \\
\hline 3 & Akinoyosooia & 33 & Komadome $^{a}$ & 63 & Tidorigai \\
\hline 4 & Aobanohue $^{\mathrm{a}}$ & 34 & Kotobuki ${ }^{a}$ & 64 & Tiyonoume ${ }^{a}$ \\
\hline 5 & Aoyanagizome ${ }^{a}$ & 35 & Kurama & 65 & Tukumozisi \\
\hline 6 & Ariake $^{a}$ & 36 & Kyoganoko $^{a}$ & 66 & Umegae \\
\hline 7 & Asahi & 37 & Kyoho $^{a}$ & 67 & Usuzyanome \\
\hline 8 & Ayanami & 38 & Kyokko $^{a}$ & 68 & Yatuhasi \\
\hline 9 & Azumakagami & 39 & Maiogi ${ }^{a}$ & 69 & Yodainoyume \\
\hline 10 & Bizyonomai & 40 & Manzairaku & 70 & Yubae $^{a}$ \\
\hline 11 & Ekironosuzu & 41 & Matunokurai & 71 & Yukiguruma \\
\hline 12 & Ginpukurin $^{a}$ & 42 & Matunoyuki & 72 & Yukihime \\
\hline 13 & Gyokkobai $^{\text {a }}$ & 43 & Mezirodai & 73 & Zansetu $^{a}$ \\
\hline 14 & Haginouwakaze & 44 & Mitaziman & 74 & Zyanomegasa $^{a}$ \\
\hline 15 & Hahanomegumi $^{\mathrm{a}}$ & 45 & Nankinkozakura $^{a}$ & 75 & Zyunihitoe \\
\hline 16 & Hanadaisyo & 46 & Nuretubame $^{a}$ & & \\
\hline 17 & Hanagatami ${ }^{a}$ & 47 & Oedo & & \\
\hline 18 & Hanaguruma $^{a}$ & 48 & Osuma $^{a}$ & & \\
\hline 19 & Hananojyo & 49 & Rasyomon & & \\
\hline 20 & Harutugedori & 50 & Sakuragawa & & \\
\hline 21 & Hatugarasu $^{a}$ & 51 & Sasanaki ${ }^{a}$ & & \\
\hline 22 & Hatuseyama $^{a}$ & 52 & Sensyo $^{a}$ & & \\
\hline 23 & Hatusugata $^{a}$ & 53 & Setugekka ${ }^{a}$ & & \\
\hline 24 & Hokutosei $^{\text {a }}$ & 54 & Sikinomine ${ }^{a}$ & & \\
\hline 25 & Huzigosi & 55 & Sirawashi ${ }^{\mathrm{a}}$ & & \\
\hline 26 & Irogisoi $^{a}$ & 56 & Sirotonbo ${ }^{a}$ & & \\
\hline 27 & Izayoi $^{\mathrm{a}}$ & 57 & Sirousagi $^{\mathrm{a}}$ & & \\
\hline 28 & Kakuremino & 58 & Sumizomegenzi ${ }^{a}$ & & \\
\hline 29 & Karabune $^{\mathrm{a}}$ & 59 & Taimen & & \\
\hline 30 & Kasuminokoromo $^{a}$ & 60 & Takatyomomoiro & & \\
\hline
\end{tabular}

aCultivars used in nested ANOVA. traces, were then calculated from the chain-code data by the procedure proposed by Kuhl and Giardina (1982). Using this procedure, we approximated the shape of each of the five petals by the first 20 harmonics, and thus calculated $80(4 \times 20)$ standardised EFDs.

The 80 coefficients could be classified into two groups related to symmetrical variation (40 coefficients, hereafter referred to as group A) and asymmetrical variation (40 coefficients, group B) (Iwata et al, 1998; Yoshioka et al, 2004). To summarise the information contained in the coefficients in each group, we performed a PCA based on a variance-covariance matrix. To determine the effect of each PC on petal shape, we recalculated the coefficients of the EFDs, letting the score on a particular PC be equal to the mean \pm 2 SD (standard deviations), while keeping the scores of the remaining components as means. We then reconstructed the petal contour shape for each score condition on the basis of the recalculated coefficients. We used the scores of the components as the characteristics of petal shape in the following analyses. We also obtained each petal area by image analysis to compare variation in this parameter.

To examine the genotypic (ie varietal) effects on PC scores among cultivars, we carried out a nested ANOVA for the scores since the samples had a hierarchical structure with four sources, that is, cultivar, plant, flower, petal. In group B, to remove the influence of the direction of curvature, we converted all the scores of the PCs to absolute values before analysis. For the nested ANOVA we used JMP4.0 (SAS Institute Inc., 2000). We also performed tests for equal variance (Snedecor and Cochran, 1989) to compare the diversity of variation in the cultivars with that in the wild populations. Then, to detect the mean shifts in variance from the wild population to the cultivars, we performed two-sample $t$-tests when two variances were not significantly different, and two-sample $t$-tests with Welch's correction when they were significantly different (Snedecor and Cochran, 1989).

\section{Results}

A good summary of the data was provided by the first four PCs for symmetrical variation (group A) and asymmetrical variation (group B). Symmetrical variation had a larger component of overall shape variation than did asymmetrical variation (Table 2). Figure 2 shows the reconstructed contours of the first four PCs of groups A.

Table 2 Eigenvalues and contributions of principal components in groups A and B

\begin{tabular}{|c|c|c|c|c|c|c|}
\hline \multirow[t]{3}{*}{ Component } & \multicolumn{3}{|c|}{ Group A } & \multicolumn{3}{|c|}{ Group B } \\
\hline & \multirow[t]{2}{*}{ Eigenvalue $^{\mathrm{a}}$} & \multicolumn{2}{|c|}{ Proportion (\%) } & \multirow[t]{2}{*}{ Eigenvalue $^{\text {a }}$} & \multicolumn{2}{|c|}{ Proportion (\%) } \\
\hline & & Of group ${ }^{\mathrm{b}}$ & Of total ${ }^{c}$ & & Of group ${ }^{\mathrm{b}}$ & Of total ${ }^{\mathrm{c}}$ \\
\hline 1 & 100.95 & 43.58 & 33.28 & 24.06 & 46.24 & 7.93 \\
\hline 2 & 86.85 & 34.55 & 28.63 & 8.75 & 16.82 & 2.88 \\
\hline 3 & 25.46 & 10.12 & 8.39 & 4.88 & 9.38 & 1.61 \\
\hline 4 & 10.16 & 4.04 & 3.35 & 3.15 & 6.05 & 1.04 \\
\hline Total variance & 251.33 & & & 52.05 & & \\
\hline
\end{tabular}

aRead eigenvalues as $x \times 10^{-5}$.

bProportion relative to the total variance of the elliptic Fourier coefficients belonging to each group.

cProportion relative to the total variance of all coefficients of both groups. 
660

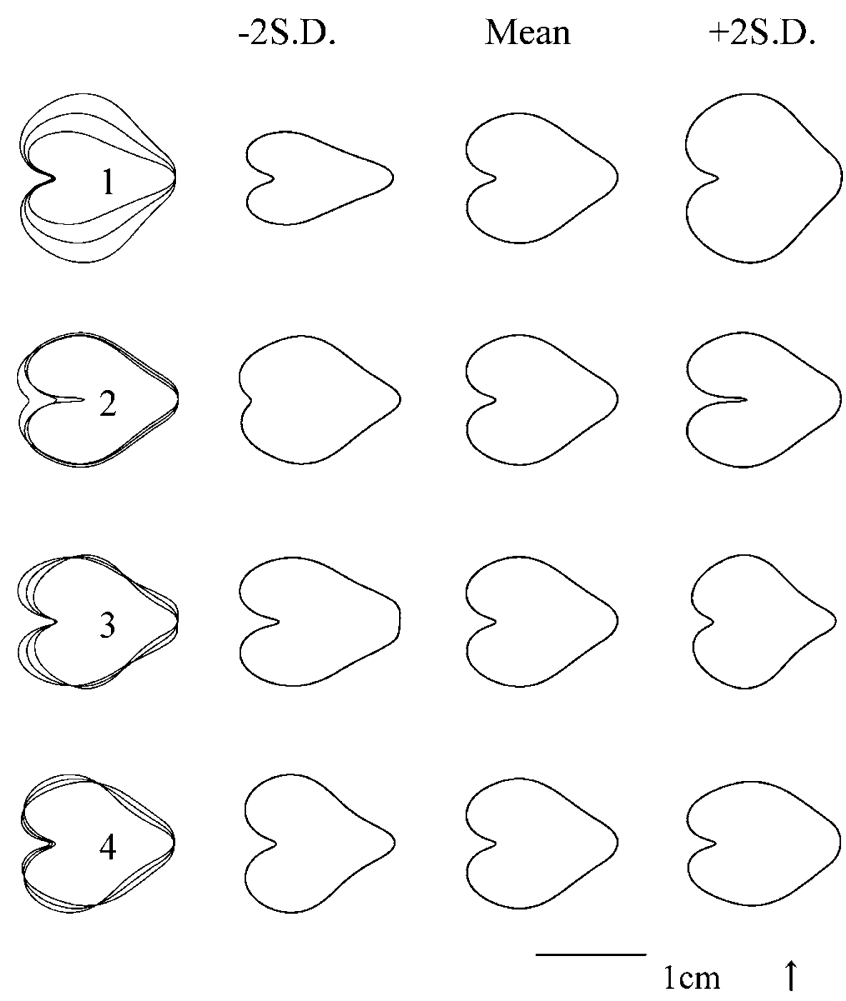

Figure 2 Effect of each principal component in group A on petal shape. Numbers 1 to 4 correspond to the first to fourth principal components, respectively. From the right, each column shows the case where the score takes $+2 \mathrm{SD}$ (standard deviations), mean and $-2 \mathrm{SD}$, and the left-most column shows the overlaid drawings of all three cases.

These reconstructed contours indicated that the first PC of group A was a good measure of the aspect ratio of the petal, which accounted for $43.6 \%$ of the symmetrical variation (Figure 2, Table 2). The second PC was associated with the depth of the head notch, and accounted for $34.6 \%$ of the symmetrical variation (Figure 2, Table 2) in group A. The third and fourth PCs were related to the curvature of the proximal and distal parts and the position of the centre of gravity, respectively. These PCs accounted for 10.1 and $4.0 \%$ of symmetrical variation, respectively (Figure 2, Table 2). By contrast, the first four PCs for group B represented asymmetrical variation, such as differences in the curvature and swell of distal and proximal parts (figure not shown).

In the nested ANOVA, the proportion of the variance in the first four PCs of group A due to genotypic (varietal) differences was overwhelmingly greater than that due to any their components of the plant hierarchy (Table 3). These results suggest that the petal shape features accounted for by these four PCs had high heritability. This suggests that they are appropriate indices for comparing petal shape variation between cultivars and wild populations, and we used these four PCs in the subsequent analysis.

By contrast, in group B, the proportions of variance due to genotypic differences were comparatively small, and the proportion due to within-flower (petal) variation was much greater (Table 3). This indicates that the effect of genotype on asymmetrical shape variation was weak.
Table 3 Proportions (\%) of variance components in the principal components of groups $\mathrm{A}$ and $\mathrm{B}$ derived from each of the four hierarchical sources (as estimated by nested ANOVA)

\begin{tabular}{lcccc}
\hline Source & $P C 1$ & $P C 2$ & $P C 3$ & $P C 4$ \\
\hline Group A & & & & \\
Variety & $88.34^{* *}$ & $74.66^{* *}$ & $72.67^{* *}$ & $74.81^{* *}$ \\
Plant & $1.28^{* *}$ & $2.32^{* *}$ & $5.06^{* *}$ & $2.33^{* *}$ \\
Flower & $3.65^{* *}$ & $2.01^{* *}$ & $2.32^{* *}$ & $2.69^{* *}$ \\
Petal & 6.73 & 21.02 & 19.96 & 20.17 \\
& & & & \\
Group B & & & & \\
Variety & $16.74^{* *}$ & $17.98^{* *}$ & $20.52^{* *}$ & $23.23^{* *}$ \\
Plant & $2.78^{* *}$ & $0.48^{\mathrm{NS}}$ & $0.57^{\mathrm{NS}}$ & $0.00^{\mathrm{NS}}$ \\
Flower & $0.00^{\mathrm{NS}}$ & $1.64^{\mathrm{NS}}$ & $1.52^{\mathrm{NS}}$ & $3.40^{* *}$ \\
Petal & 80.48 & 79.90 & 77.39 & 73.37 \\
\hline
\end{tabular}

**P $<0.01$; NS, nonsignificant.

Therefore, we excluded the PC scores of group B from the subsequent analysis.

A test for equal variance (two-tailed test) showed that variation in the first $\left(F_{(74,263)}=1.68 ; P \leq 0.01\right)$ and third $\left(F_{(74,263)}=4.42 ; P \leq 0.01\right)$ PCs of group A and in petal area $\left(F_{(74,263)}=18.58 ; P \leq 0.01\right)$ were significantly greater in the cultivars than in the wild populations. In contrast, variation in the second $\left(F_{(74,263)}=1.05 ; P>0.01\right)$ and fourth $\left(F_{(74,263)}=1.20 ; P>0.05\right)$ PCs were not significantly different between the cultivars and the wild populations. To test the difference in mean between the cultivars and wild populations, we performed two-sample $t$-tests with Welch's correction for the unequal-variance cases, that is, the first and third PCs and petal area, and ordinal twosample $t$-tests for the equal-variance cases, that is, the second and fourth PCs. The results of these tests (twotailed) showed that there were significant differences at the $1 \%$ level in the means of the second and third PCs and petal area, but not for the first and fourth PCs. The frequency distributions (Figure 3) clearly reflect the differences in the variance and means of the petal shape features and petal area between the cultivars and wild populations.

\section{Discussion}

We detected the quantitative changes that have occurred in the petal shape of $P$. sieboldii during domestication. Petals of cultivars had a shallower head notch (second PC) and were more fan-shaped (third PC) than those of the wild $P$. sieboldii. The level of variation in petal shape in the cultivars was equal to (second and fourth PCs) or greater than (first and third PCs) that in the wild populations. These diversities and transitions of petal shape may be the result of previous breeding manipulations, such as crossing and selection. Perhaps, the most interesting result of this study was the great transition in the third PC (Figure 3). The fact that many cultivars have very fan-shaped petals could indicate that consumers prefer this shape, or that such transitions have arisen indirectly through selection on other characteristics such as flower colour and pattern.

Although we could not grow all plants under the same environmental conditions, the large differences in petal form and in mean petal area between the cultivars and the wild populations (Figure 3) indicated that gigantism 

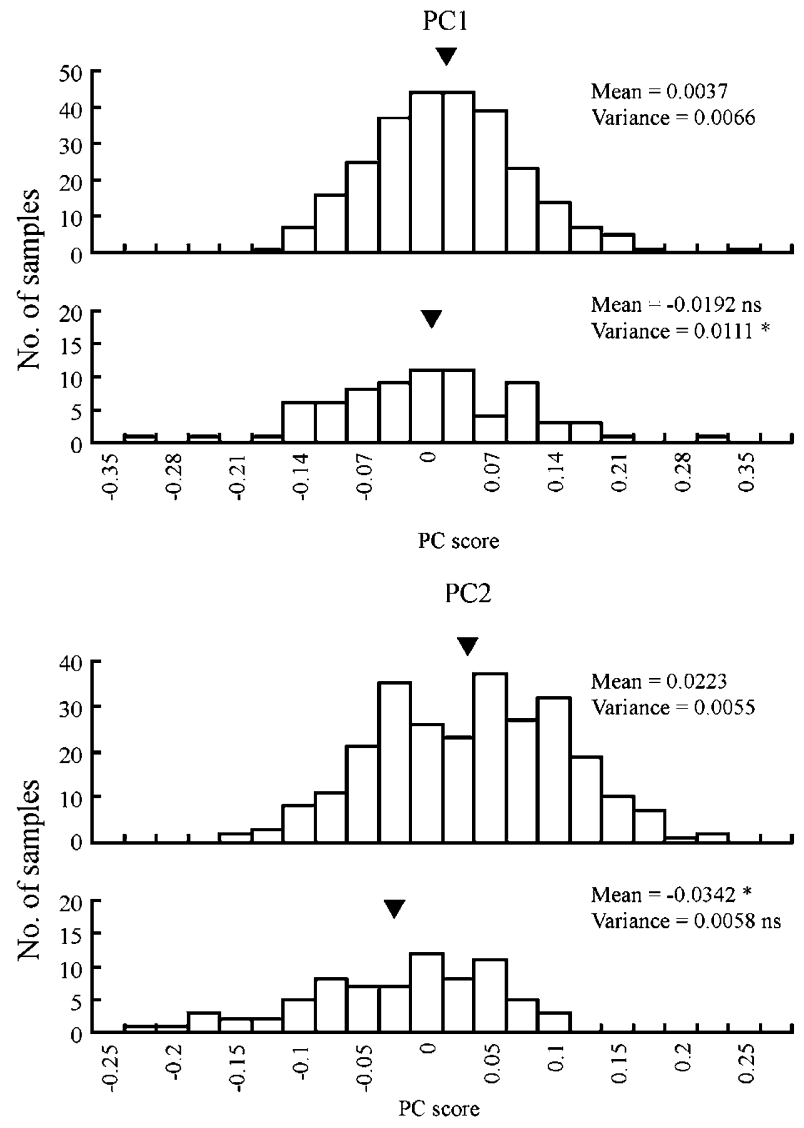

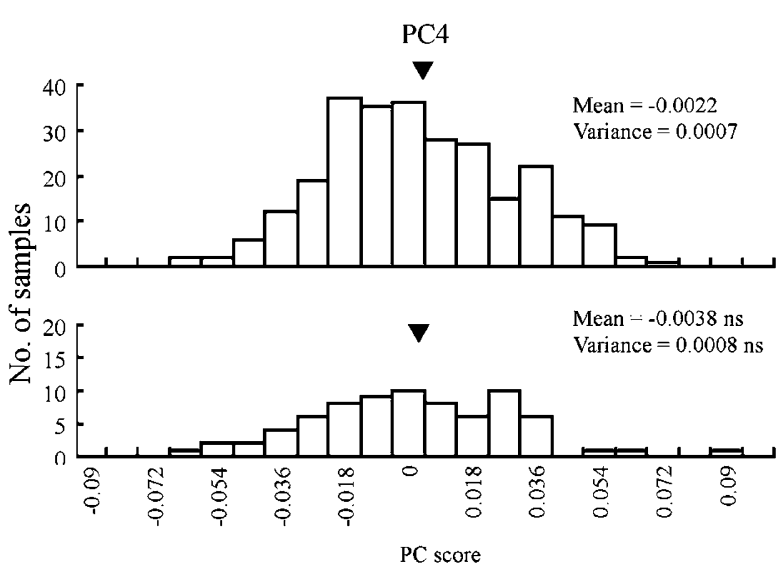

Petal area

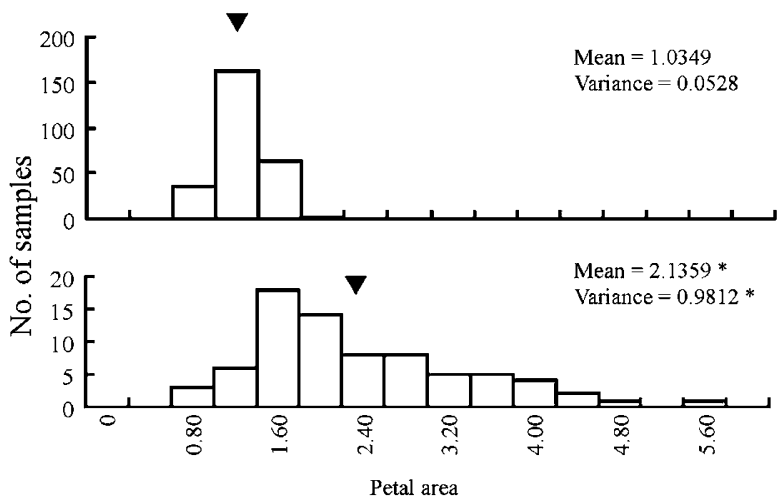

PC3

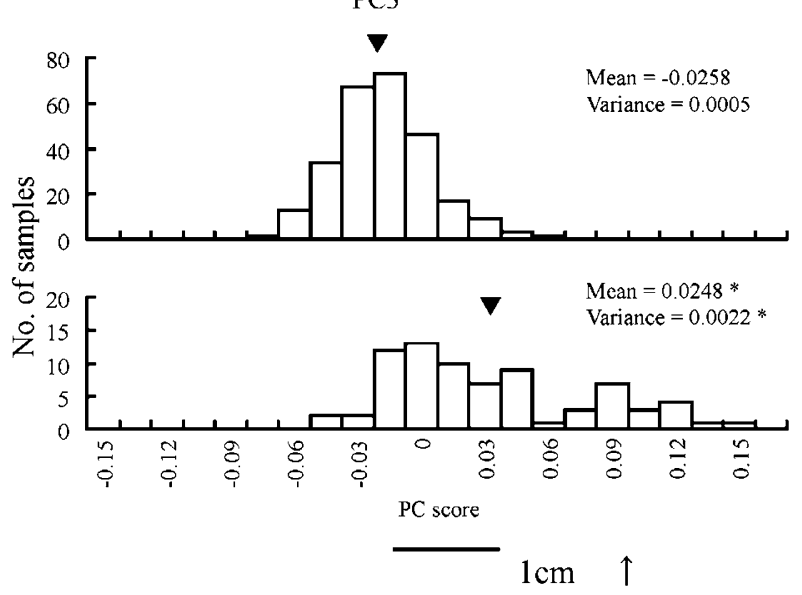

Figure 3 Distribution of the first to fourth principal component (PC) scores and petal area $\left(\mathrm{cm}^{2}\right)$ among cultivated and wild Primula sieboldii. Upper, wild populations; lower, cultivars. $\mathbf{\nabla}$ indicates the mean of the cultivars or wild populations.

in the $P$. sieboldii petal has been caused by strong selection to meet consumer preferences.

From a breeding point of view, the great diversity and transition of the third PC and petal area in the cultivars indicate that selection effects on these characters were comparatively large. In contrast, there was no distinction between the cultivars and wild populations in the fourth PC. The contribution of the fourth PC to the total variance was as low as $3.35 \%$ (Table 2). It is difficult for humans to detect such small variation, and we can assume that breeders could not focus their selection intentionally on the fourth PC.
Although wild P. sieboldii and many cultivars are diploid, some cultivars are triploid and tetraploid (Yamaguchi, 1973a,b). Of the 75 cultivars used in this study, four were triploid ('Ekironosuzu', 'Kakuremino', 'Mejirodai' and 'Sirawashi'). In floriculture crops, polyploidisation often brings higher ornamental values, such as a bigger flower and a thicker petal (Ohkawa, 1995; Ukai, 2003). However, Torii (1985) reported that polyploidisation could not yield a flower much larger than that of the diploid in P. sieboldii. In this study, although triploid cultivars tended to have high scores for the third PC and a large petal area, there was no clear distinction 
between the triploid cultivars and the other cultivars in terms of petal shape and size. This indicates that polyploidisation probably does not have a huge impact on petal shape, just as Torii (1985) reported for flower size.

In terms of plant evolution under domestication, the fact that $P$. sieboldii cultivars were probably developed from only a limited number of wild populations may have restricted the genetic diversity of cultivated $P$. sieboldii in the initial stages of domestication (Torii, 1985; Honjo et al, 2002). Nevertheless, our results show that petal-form variation in the cultivars is equal to, or greater than, that in wild populations. Directional selection can establish characters or character combinations never known before (Ladizinsky, 1998). In P. sieboldii, for ornamental purposes, there could have been directional selection towards a large, very fan-shaped petal with a shallow head notch. Directional selection, however, has not necessarily been responsible for the increase in petal-form diversity in cultivars. One possibility is that petal-form diversity has serendipitously accompanied selection for other floral characteristics, such as petal colour pattern. In fact, the cultivars we studied had various colour patterns. Another possibility is that heterogeneous consumer preferences for petal form have caused this diversity in the cultivars. We can easily imagine that consumer preference with regard to ornamental characters is much more diverse than for other characters: that is, artificial selection is multidirectional rather than unidirectional, because there are a number of ornamental values. Through a combination of these inadvertent selections and directional selection, the 300-year-long breeding process might have served to enlarge and maintain petal-form diversity in cultivars.

$P$. sieboldii is now in danger of extinction in Japan (Ministry of the Environment, 2004). Most of the wild populations considered as the source populations of the present cultivars have been practically extinguished. We might, therefore, assume that petal-form variation in wild populations has decreased over the last 300 years, making the diversity and transitions of cultivars comparatively larger. In that case, we might have expected that the diversity of all petal-form characters would have decreased. This appears not to be the case for PC2 and PC4, indicating that aspects of petal-form diversity have been maintained, despite the reduction in population number and size.

Our results clearly suggest the 'domestication syndrome' occurring in floriculture, which in this case is characterised by gigantism and morphological diversification. In addition, using EF-PCA, we were able to reveal that the various components of flower shape have changed to different extents from the wild population. This phenomenon could be explained by the nature of the historical breeding process (eg strength of selection pressure and direction of selection on the different attributes), or biological factors (eg heritability, linkage and pleiotropy). Our approach could be used to quantify the impacts of domestication on many other horticulture crops.

\section{Acknowledgements}

We thank Dr I Washitani of the University of Tokyo, Dr J Yokoyama of the Tohoku University, Mr M Honjo,
Ms N Kitamoto, Mr A Koga of the University of Tsukuba, and C Nakano of the University of Tokyo for their kind help, especially with the sampling of flowers in wild populations. We also thank Dr T Handa of the University of Tsukuba, Mr T Matsumoto of the Saitama Prefecture Agriculture and Forestry Research Center for sampling the flowers of cultivars, and Dr M Laurenson of the Horticulture and Food Research Institute of New Zealand for critical reading of the manuscript.

\section{References}

Freeman H (1974). Computer processing of line drawing images. Comput Surv 6: 57-97.

Furuta N, Ninomiya S, Takahashi S, Ohmori H, Ukai Y (1995). Quantitative evaluation of soybean (Glycine max L., Merr.) leaflet shape by principal component scores based on elliptic Fourier descriptor. Breeding Sci 45: 315-320.

Gepts P (1993). The use of molecular and biochemical markers in crop evolution studies. Evol Biol 27: 51-94.

Hawkes JG (1983). The Diversity of Crop Plants. Harvard University Press: MA. pp 1-26.

Honjo M, Handa T, Tsumura Y, Ohsawa R (2002). Which natural populations are the origin of Japanese garden species in Primula sieboldii? Breeding Res (Ikusyugaku Kenkyu) 4: 414 [in Japanese].

Iwata H, Niikura S, Matsuura S, Takano Y, Ukai Y (1998). Evaluation of variation of root shape of Japanese radish (Raphanus sativus L.) based on image analysis using elliptic Fourier descriptor. Euphytica 102: 143-149.

Iwata H, Nesumi H, Ninomiya S, Takano Y, Ukai Y (2002). The evaluation of genotype $\times$ environment interactions of citrus leaf morphology using image analysis and elliptic Fourier descriptors. Breeding Sci 52: 243-251.

Iwata H, Ukai Y (2002). Shape: a computer program package for quantitative evaluation of biological shapes based on elliptic Fourier descriptors. J Hered 93: 384-385.

Kuhl FP, Giardina CR (1982). Elliptic Fourier features of a closed contour. Comput Graphics Image Process 18: 236-258.

Ladizinsky G (1998). Plant Evolution under Domestication. Kluwer: Dordrecht. pp 111-126.

McLellan T (1993). The roles of heterochrony and heteroblasty in the diversification of leaf shapes in Begonia dregei (Begoniaceae). Am J Bot 80: 796-804.

Ministry of the Environment (2004). Japan Integrated Biodiversity Information System. http://www.biodic.go.jp/index_e.html. 2 Feb. 2004.

Ohkawa K (1995). Kakiengeisouron. Yokendo Ltd: Tokyo. pp 32-49 [in Japanese].

Ohsawa R, Tsutsumi T, Uehara H, Namai H, Ninomiya S (1998). Quantitative evaluation of common buckwheat (Fagopyrum esculentum Moench) kernel shape by elliptic Fourier descriptor. Euphytica 101: 175-183.

Rohlf FJ, Archie JW (1984). A comparison of Fourier methods for the description of wing shape in mosquitoes (Diptera: Culicidae). Syst Zool 33: 302-317.

SAS Institute Inc. (2000). JMP statistics and graphics guide, version 4. SAS Institute Inc.: Cary, NC.

Snedecor GW, Cochran WG (1989). Statistical Methods, 8th edn. Iowa State University Press: Ames, IA. pp 83-106.

Suzuka T (1975). Nihonsakurasou. NHK-shuppan: Tokyo. pp 113-167 [in Japanese].

Torii T (1985). Sakurasou. Nippon Television Network Corporation: Tokyo. pp 114-123 [in Japanese].

Toyohara H, Irie K, Ding W, Iwata H, Fujimaki H, Kikuchi F et al (2000). Evaluation of tuber shape of yam (Dioscorea alta L.) cultivars by image analysis and elliptic Fourier descriptors. SABRAO J Breeding Genet 32: 31-37.

Ukai Y (2003). Plant Breeding. University of Tokyo Press: Tokyo. pp 222-270 [in Japanese]. 
Washitani I (1998). Sakurasounome. Chijinshokan Co., Ltd: Tokyo pp 18-38 [in Japanese].

White R, Rentice HC, Verwist T (1988). Automated image acquisition and morphometric description. Canad J Bot 66: 450-459.

Yamaguchi S (1973a). Cytogenetical studies in Primula sieboldi E. Morren I. Chromosome numbers of 80 cultivars and related wild species. Jpn J Breeding 23: 86-92.
Yamaguchi S (1973b). Cytogenetical studies in Primula sieboldii E. Morren II. Meiosis in the triploid cultivars. Jpn J Breeding 23: 320-324.

Yoshioka Y, Iwata H, Ohsawa R, Ninomiya S (2004). Analysis of petal shape variation of Primula sieboldii E. Morren by elliptic Fourier descriptors and principal component analysis. Ann Bot 94: 657-664. 